\title{
DROWNING ASSOCIATED DIATOMS IN SRI LANKA
}

\author{
P.G.L. Gunatilake $\underline{\&}$ Induwara Gooneratne \\ Department of Forensic Medicine, Faculty of Medicine, \\ University of Peradeniya, Sri Lanka.
}

Drowning can cause death by submersion in a fluid. Each year many people die in Sri Lanka due to drowning. There are different ways and circumstances people drown in fluids, the most common fluid being water. There can be instances where victims are drowned / disposed to water subsequent to ñरillingò. In these instances it is important to identify whether one died because of drowning or due to some other cause. Diatom studies have been helpful in determining the cause of death in drowning associated deaths.

Diatoms are among the well known water planktons. They are autotrophic in nature and different genera are found in both marine and fresh habitats. When drowning takes place, diatoms enter into the lung cavity of a person through the aspirated water. The water exerts a pressure on lung cavity and facilitates entering diatoms into the blood. Thus diatoms can enter into heart, liver, kidney, brain and bone marrow. As diameter and thickness of lung alveoli remains very small it is not possible for all the diatoms to penetrate into the body organs through the lung cavity. The diatoms which can penetrate through this capillary network are called ñDrowning Associated Diatomsò (DAD).

Analysis of such DAD present in the lungs, liver, spleen, blood and bone marrow has for many years been undertaken as a reliable test in forensic practice in suspected downing cases. Research on forensically significant diatoms in Sri Lanka are very little and scanty. Although it is well known that diatoms are associated with drowning, which types of diatoms are commonly found in drowning in a Sri Lankan context is not documented.

The objective of this study was to identify the DADs (the genus) amongst the samples referred to the department for diatom analysis and document them. The Department of forensic Medicine at University of Peradeniya receives referrals for diatom analysis from around the country and this documentation serves as an initial step in identifying which diatom types are commonly associated with drowning cases.
Thirty five tissue samples (belonging to thirty five different suspected drowning cases) sent to the department with a history of drowning were analyzed with a view to identify the diatom present. The samples included lungs, kidneys and bone marrow. A routine slide preparation was done adhering to nitric acid digestion and centrifuge method, (Peabody, A.J -1977). The diatoms were identified through a light microscope.

In this study Genus Cyclotella was found to be the most frequent (more than 50\%) and then Navicula and Nitzschia were found to be frequent respectively. In addition Frustulia, Gomphonema, Pinnularia, Cymbella and Cocconeis were also identified in the tissues.

It appears that the shape of the diatom plays a role in drowning. When the shape is more elongated thin and small in size it is presumed to penetrate lung tissues and enter into blood stream easily. The other consideration would be the concentration of the specific type of diatom in the water where the drowning took place. It can be asserted that more the concentration of a specific type of a diatom, better the chance of getting in to the lungs and thereafter to the blood stream. However the concentration of specific type of diatoms are not routinely estimated. The nature and flexibility of the cell wall of the diatom cell is another factor that facilitates this process. However with physical force almost all types of diatoms can be associated in the blood stream. It must be also noted that there can be diatoms in our blood or in our tissues under normal condition due to the availability of diatoms in drinking water. It can be common among those who drink water from wells, rivers and tanks etc. Therefore it is important to assess the victimsô routine water sample also in order to provide a comprehensive opinion. However under such condition the presence of diatoms can be minimal.

In conclusion it can be stated that the following genus are DADs in Sri Lanka; Cyclotella sp., Navicula sp., Nitzschia sp., Frustulia sp., Gomphonema sp., Pinnularia sp., Cymbella sp. and Cocconeis sp. 
Some identified DADs in Sri Lanka.

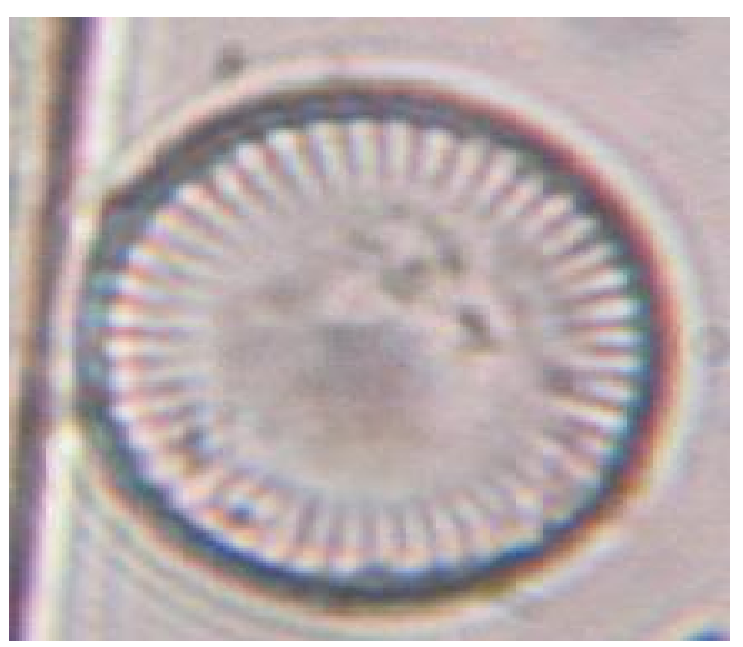

Cyclotella sp.

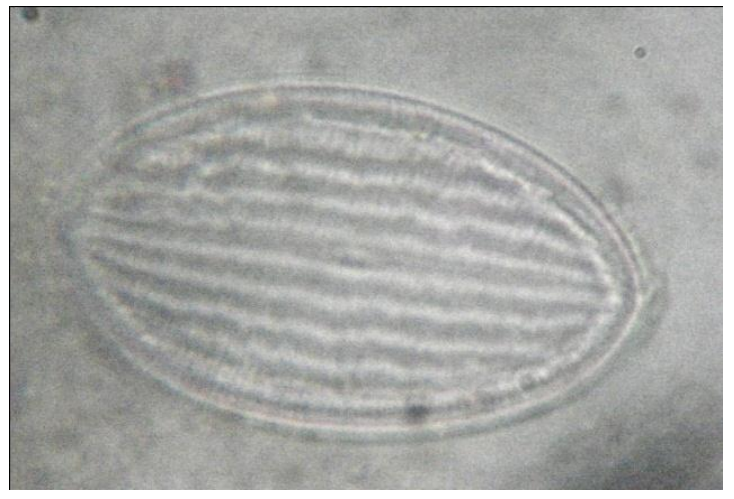

Cocconeis sp.

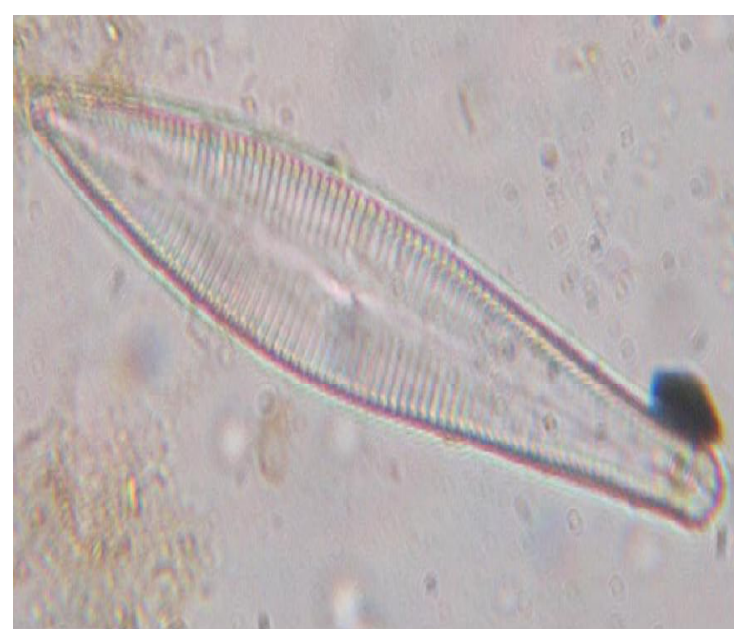

Gomphonema sp.

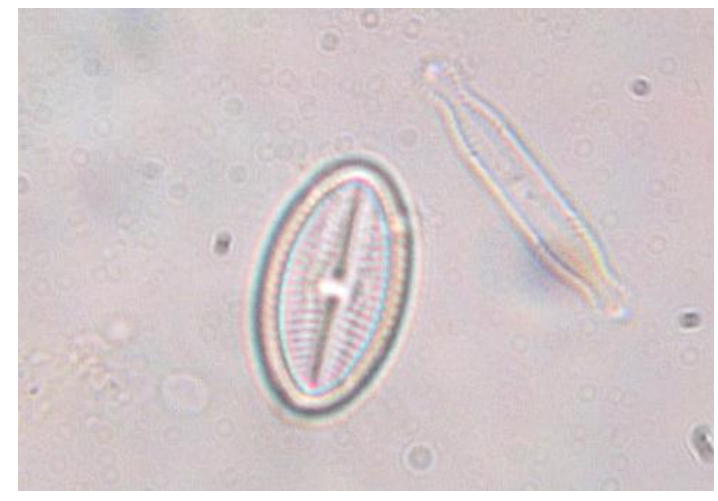

Navicular sp.

\section{REFERENCES}

1. F. E. Round, R. M. Crawford and D. G. Mann. (1990)Diatoms: Biology and Morphology of the Genera. Cambridge University Press. London

2. Peabody, A.J. (1977)Diatoms in Forensic Science. Journel of Forensic Science Society. Vol 17,Issue 2-3, PP 81-7.

3. Singh R, Singh R, Kumar S, Thakar MK. Forensic Analysis of Diatoms- A Review. Anil Aggrawal's Internet Journal of Forensic Medicine and Toxicology 2006; Vol. 7, No. 2 (July - December 2006): 